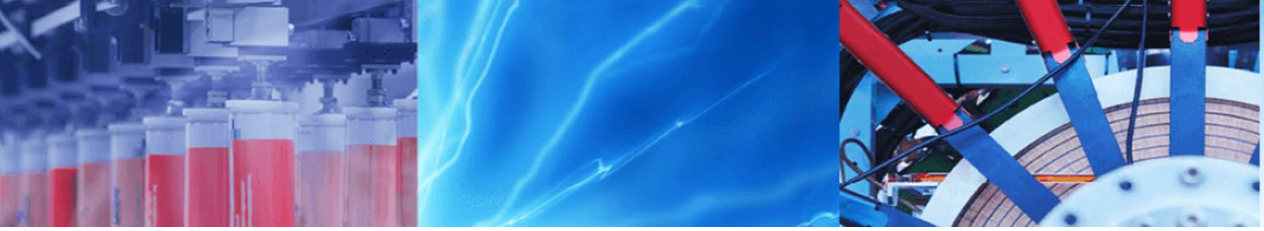

Research Article

\title{
Effect of bonding temperature and holding time on properties of hollow structure diffusion bonded joints of TC4 alloy
}

\author{
Wenjing Gao ${ }^{1}$. Shuming Xing ${ }^{1}$ Junxiang Lei $^{2}$
}

Received: 15 June 2020 / Accepted: 26 October 2020 / Published online: 8 November 2020

(c) Springer Nature Switzerland AG 2020, corrected publication 2020

\begin{abstract}
The hollow structure commonly used in aerospace field is generally formed by the SPF/DB, but its disadvantages lead to surface groove and complex internal structure difficult to form. In this paper, the method of milling combined with diffusion bonding is used to improve the defect. Diffusion bonding of TC4 titanium alloy hollow structure was carried out at temperature ranging from $800^{\circ} \mathrm{C}$ to $900^{\circ} \mathrm{C}$ for $10 \sim 30 \mathrm{~min}$. The interfacial bonding ratio, deformation ratio, microstructures, microhardness and mechanical properties of the diffusion bonded joints were investigated. The results show that joints with high bonding quality can be obtained when bonded at $850^{\circ} \mathrm{C}$ and $900{ }^{\circ} \mathrm{C}$ for $20 \sim 30 \mathrm{~min}$. The joint bonding ratio is more than $92 \%$, the tensile strength is $952 \mathrm{MPa}$, and the deformation ratio is maintained at about $10 \%$. The microhardness of the TC4 alloy hollow structural joint increases with the increase in bonding temperature, showing a trend of "high in the middle and low on both sides", and it has a peak value (HV472) when bonding time is prolonged up to $30 \mathrm{~min}$. The findings indicate that qualified workpiece can be obtained by the process.
\end{abstract}

Keywords TC4 titanium alloy · Hollow structure · Diffusion bonding $\cdot$ Microstructure $\cdot$ Mechanical properties

\section{Introduction}

Titanium alloys are used as structural materials in many engineering fields especially in aerospace and military fields $[1-3]$ due to their excellent properties such as low density, high specific strength, excellent corrosion resistance and heat resistance $[1,4]$. TC4 (Ti-6Al-4 V) alloy is the most widely used titanium alloy at present, which accounts for about half of the total amount of titanium alloy $[5,6]$. It has a strong comprehensive performance, known as the "flagship alloy" of the titanium alloy industry, and many other titanium alloys can be regarded as its modified [7]. However, TC4 alloy has been recognized as one of the most difficult-to-machine materials [8]. Its low thermal conductivity and high processing cost have been the bottleneck of its development [9-11]. Therefore, the new technology to solve the problem of titanium alloy processing has become the focus of researches [8]. Diffusion bonding (DB) is a solid-phase joining technique with few defects and high precision [12-14]. In the process, there is no melting and macroscopic plastic deformation of metals, and the bonding is achieved directly by the diffusion of solid phase atoms. From the view of bondability, diffusion bonding enables reliable bonding between various materials and some special structures, especially dissimilar materials and hollow structure [15-17]. Lin et al. [18] through a large number of experiments, put forward the general technical parameters of diffusion bonding of TC4 titanium alloy range: suitable bonding temperature $900-950{ }^{\circ} \mathrm{C}$, bonding pressure $1-5 \mathrm{MPa}$, holding time $30 \sim 180$ minutes. Zhang et al. [19] studied the diffusion bonding of TC4 alloy under small axial pressure

\footnotetext{
$\triangle$ Wenjing Gao, 18116008@bjtu.edu.cn | 'School of Mechanical, Electronic and Control Engineering, Beijing Jiaotong University, Beijing 100044, China. ${ }^{2}$ School of Materials Science and Engineering, University of Shanghai for Science and Technology, Shanghai 200093, China.
} 
of $0.5 \mathrm{MPa}$. The bonding temperature was $860^{\circ} \mathrm{C}, 890^{\circ} \mathrm{C}$ and $920^{\circ} \mathrm{C}$, holding time was $1 \mathrm{~h}$. Tensile test and Charpy impact test were conducted to evaluate the joint strength and toughness. Yuan et al. [20] conducted the diffusion bonding experiment, and the bonding temperature was $775,800,850$ and $900^{\circ} \mathrm{C}$, bonding time was $5,10,15$ and $30 \mathrm{~min}$, and the pressure was $10 \mathrm{MPa}$. The results show that the plastic deformation and creep mechanisms of void closure are dominated in the early stage or at low bonding temperature, with increasing bonding time or temperature, the surface diffusion and interface diffusion mechanisms act as the dominated matter for voids elimination. E. Yakushina et al. [21] studied the influence of ultra-fine-grained (UFG) and coarse-grained (CG) microstructure of Ti-6Al-4 $\mathrm{V}$ alloy on the strength of DB joint. The results indicate that the best quality of the samples bonded at $725^{\circ} \mathrm{C}$ was obtained for UFG samples, which demonstrated notably higher shear strength for both 2 and $4 \mathrm{~h}$ cycles when compared with CG samples. Han et al. [22] studied the SPF/DB of four-layer plate structures by pneumatic forming. The optimum parameters of diffusion bonding were $930^{\circ} \mathrm{C}, 30 \mathrm{~min}$ and $10 \mathrm{MPa}$.

In aerospace industry, TC4 alloy hollow structure is often used to achieve the purpose of lightweight [23-25]. Hollow structural parts are often used in aircraft panel, cabin door, access cover, missile rudder, engine blade and other parts [26]. The structure is not completely hollow, and the interior has stiffeners, which can meet the requirements of strength and realize lightweight targets [23]. The advantages of diffusion bonding are very suitable for solving the internal bonding problem of the hollow structure. At present, the use of SPF/DB to form the TC4 hollow structure is the mainstream research. It has the advantages of high efficiency and the integrity of forming parts. However, it is easy to produce groove defects on the surface of parts $[22,27-30]$. Therefore, in order to overcome the defects, the method of forming TC4 hollow structures by diffusion bonding is studied in this paper. Taking the rudder surface as the object, the structure design and diffusion bonding experiment are studied. The proper process parameters of the bonding joint are obtained and their effects on diffusion bonding forming quality are discussed.

\section{Design and experimental}

\subsection{Structural design}

The research object of this paper is the rudder surface, and it is a hollow structure. It has strict requirements for mass and center of mass, as shown in Table 1. Therefore, it is necessary to design the position, width and depth of
Table 1 Design requirements and results of the rudder surface

\begin{tabular}{|c|c|c|}
\hline \multirow[t]{2}{*}{ Requirements } & Mass & $440 \sim 500 \mathrm{~g}$ \\
\hline & Center of mass & $\begin{array}{l}\text { Within the } \\
-1 \sim 4 \mathrm{~mm} \text { range } \\
\text { of the axle wire }\end{array}$ \\
\hline \multirow[t]{5}{*}{ Design results } & Milling depth & $3.75 \mathrm{~mm}$ \\
\hline & The skin thickness & $1.25 \mathrm{~mm}$ \\
\hline & Stiffener width & $1 \mathrm{~mm}$ \\
\hline & Mass & $474 \mathrm{~g}$ \\
\hline & $\begin{array}{l}\text { Center-of-mass } \\
\text { coordinate }\end{array}$ & $\begin{array}{r}58.12,83.69 \\
-2.84 \mathrm{~mm}\end{array}$ \\
\hline
\end{tabular}

stiffener so as to meet the requirements and the using strength. Build the rudder surface part model by using 3D modeling software, adjust the width and depth of model to meet the requirements. The design results are shown in Table 1 and Fig. 1.

According to the design result of the rudder surface, the test parts are designed and manufactured (Fig. 2b). The width and depth of the stiffener are consistent with the design of the rudder surface, in order to ensure the reliability of the test results. The size of specimen is $\varphi 50 \times 5 \mathrm{~mm}$, and the width of the diffusion bonding joint is $1 \mathrm{~mm}$ (Fig. 2a).

\subsection{Experimental}

\subsubsection{Material and treatment}

The material used in the experiment is a rolled and annealed TC4 (Ti-6Al-4V) titanium alloy, supplied by AVIC Beijing aeronautical manufacturing technology research institute. TC4 alloy is the phase titanium alloy for medium strength, in which the Al element is a stable element of phase structure, and the $V$ element is a stable element of phase structure. Its chemical composition and mechanical properties are shown in Table 2. The microstructure of the material is observed by optical microscope, which consists of bright $\alpha$ and black $\beta$ phases, as shown in Fig. 3 .

Specimen pretreatment should be carried out before the diffusion bonding experiment. The first step is to use abrasive paper to grind, because the surface of specimen is machined by finish turning, the roughness is Ra0.8, so it is smoother. Use 1000-3000\# abrasive paper grinding surface in turns, until the macro-surface is bright and no scratches, and then washed with ethyl alcohol to remove impurities. Put the specimen into the ultrasonic cleaner to clean, the cleaning time is $15 \mathrm{~min}$, and finally dry it off. When the specimen is fixed with a cylindrical pin, put it into the graphite mold and ready for diffusion bonding experiment, as shown in Fig. 4 a. 

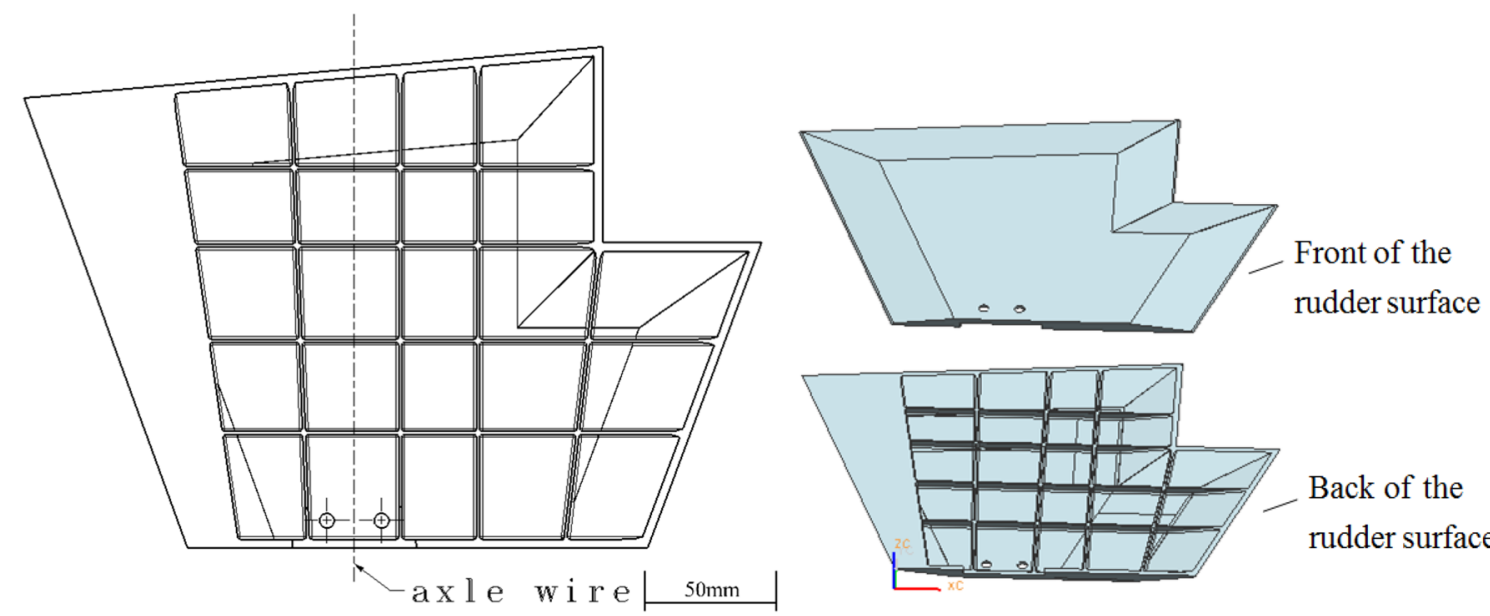

Back of the rudder surface

Fig. 1 Design result drawing of rudder surface

(a)
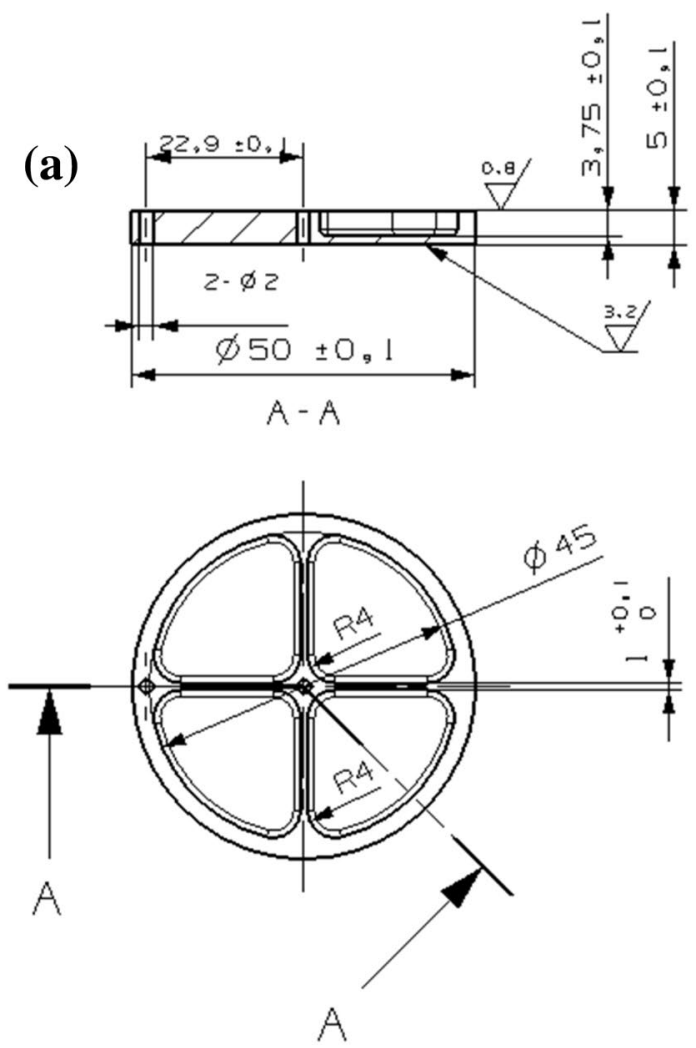

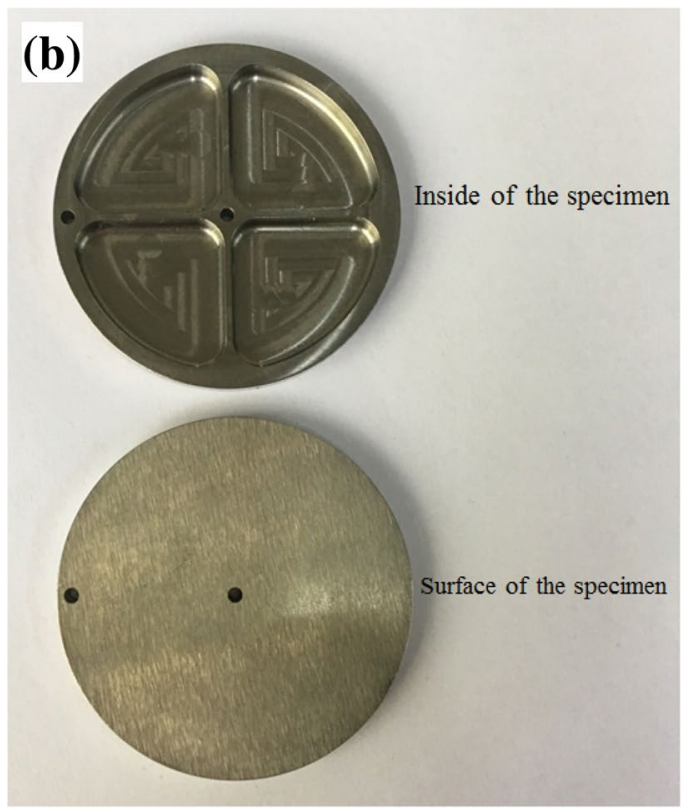

Fig. 2 Diffusion bonding specimen for diffusion bonding: a specimen drawings; $\mathbf{b}$ actual specimens

Table 2 Chemical composition and mechanical properties of TC4 alloy used in the experiment

\begin{tabular}{|c|c|c|c|c|c|c|c|c|c|c|c|c|}
\hline \multirow[b]{2}{*}{ Elements } & \multicolumn{8}{|c|}{ Chemical composition of TC4 (wt.\%) } & \multicolumn{4}{|c|}{ Mechanical properties } \\
\hline & Al & V & $\mathrm{Ti}$ & $\mathrm{Fe}$ & C & $\mathrm{N}$ & $\mathrm{H}$ & $\mathrm{O}$ & $\sigma_{b} / \mathrm{MPa}$ & $\sigma_{0.2} / \mathrm{MPa}$ & $\psi / \%$ & $\delta / \%$ \\
\hline Nominal & $5.5 \sim 6.8$ & $3.5 \sim 4.5$ & Bal. & 0.30 & 0.10 & 0.05 & 0.015 & 0.20 & 980 & $\geq 825$ & 25 & 10 \\
\hline
\end{tabular}




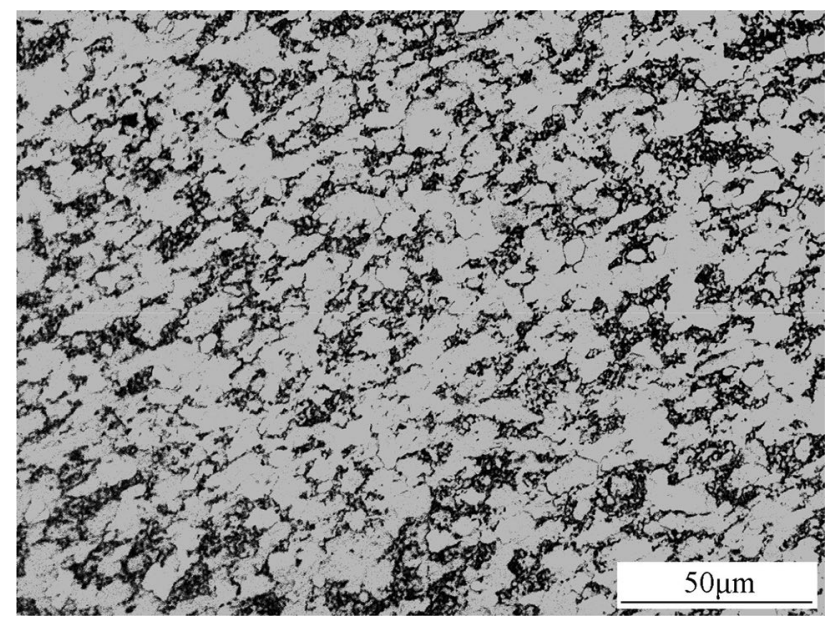

Fig. 3 Microstructure of TC4 alloy used

The equipment used in diffusion bonding experiment is vacuum hot-pressing sintering furnace, as shown in Fig. $4 \mathrm{~b}$, the model is zt-40-20y. The maximum pressure of the equipment is $20 \mathrm{~T}$, the ultimate cold vacuum degree is $6.67 \times 10^{-3} \mathrm{~Pa}$, the size of work area is $\varphi 160 \times 160 \mathrm{~mm}$, the internal pressure head diameter is $\varphi 85 \mathrm{~mm}$, the pressure and displacement can be tracked and controlled automatically, and the displacement precision is $0.05 \mathrm{~mm}$. The heating element is graphite carbon tube, its highest heating temperature can reach $2000^{\circ} \mathrm{C}$ and the continuous working temperature is $1850^{\circ} \mathrm{C}$. The temperature measuring element is tungsten-rhenium thermocouple, and its temperature control precision is $\pm 2{ }^{\circ} \mathrm{C}$. The equipment has the advantages of fast heating rate and uniform temperature field, and is mainly used for vacuum sintering, high temperature hot pressing, etc. [31]. It can meet the requirements of temperature, pressure and vacuum in diffusion bonding experiment, and accurately control the heating
Table 3 Diffusion bonding experimental scheme

\begin{tabular}{llll}
\hline Number & Temperature $\left({ }^{\circ} \mathrm{C}\right)$ & Time $(\min )$ & Pressure $(\mathrm{MPa})$ \\
\hline 1 & 800 & 30 & 12 \\
2 & 850 & 10 & 12 \\
3 & 850 & 20 & 12 \\
4 & 850 & 30 & 12 \\
5 & 900 & 30 & 12 \\
\hline
\end{tabular}

rate, heating temperature and holding time through the computer program. Put the assembled specimen and mold into the furnace, and enter the temperature control curve by computer programming according to each test parameter in Table 3. The temperature control curve is shown in Fig. 5 (Take temperature curve of bonding temperature $850^{\circ} \mathrm{C}$, holding time $30 \mathrm{~min}$ and pressure $12 \mathrm{MPa}$ as an example). When the degree of vacuum reaches $10 \mathrm{~Pa}$, the program starts and begins to heat up. According to Table 3 , after heating to the test temperature, keep the temperature constant and apply pressure for the set time. Then, the specimen was furnace-cooled to room temperature. The whole test process lasted about $12 \mathrm{~h}$.

\subsubsection{Microstructure analysis and mechanical properties testing}

After the diffusion bonding experiment, the stiffener of the specimen was cut off by WEDM, and the microstructure analysis and mechanical properties testing were carried out. Before analysis and testing, specimens were grinded by $240-7000 \#$ abrasive paper in turns and the surface of specimen was polished into a mirror surface and then corroded. The ratio of corrosion liquid is $\mathrm{HF}: \mathrm{HNO}_{3}: \mathrm{H}_{2} \mathrm{O}=1: 3: 10$ (volume ratio), and the corrosion
Fig. 4 a Schematic diagram of specimen assembly; b Diffusion bonding equipment
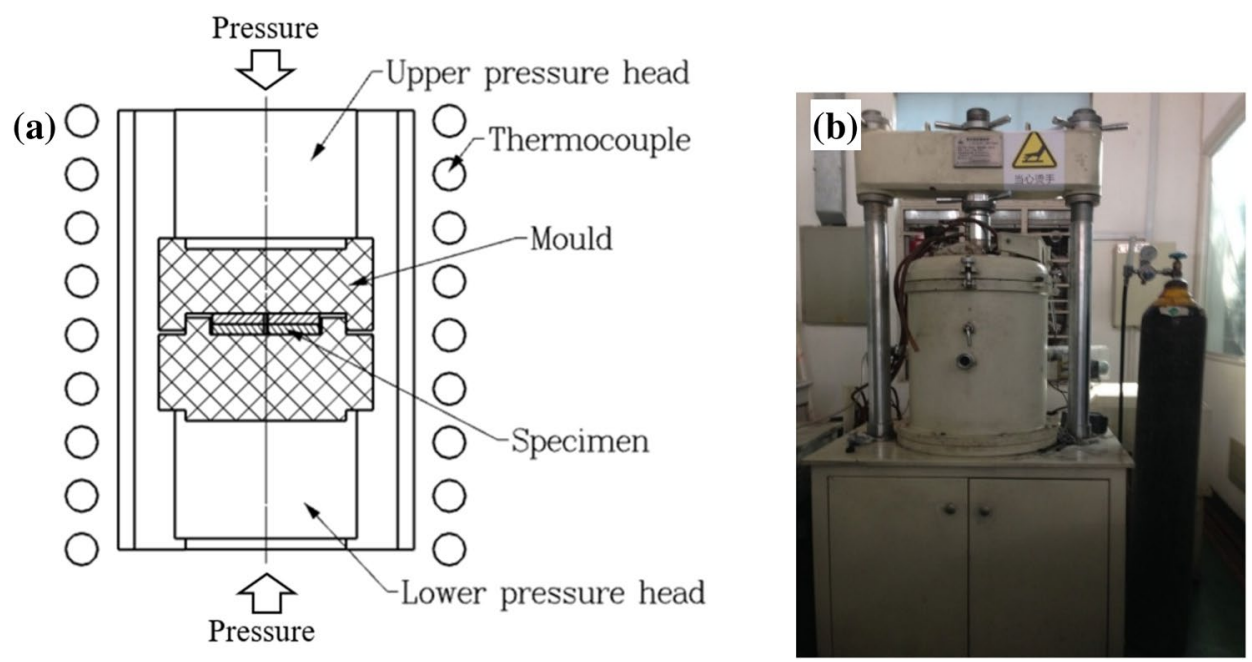


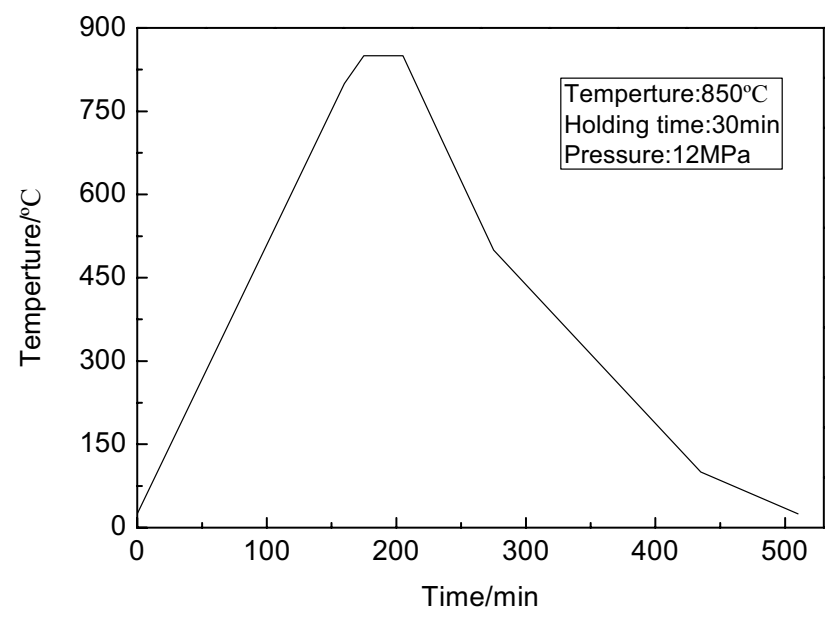

Fig. 5 Temperature control curve

time is $10 \mathrm{~s}$. The microstructure of diffusion bonding joint was observed by optical microscope (OM), and the bonding ratio was calculated by Image-Pro Plus software. The bonding ratio is an important index to evaluate the quality of diffusion bonding. The higher the bonding ratio, the better the quality of diffusion bonding and the formula of bonding ratio is as follows:

$\varepsilon_{L}=\frac{L_{0}-L_{1}}{L_{0}} \times 100 \%$

where $\varepsilon_{L}$ is joint bonding ratio, $L_{0}$ is bonding interface length, $L_{1}$ is unbonding and defect section length.

Tensile tests are carried out with a Zwick micro-tensile tester. The stretching speed is set to $2.4 \times 10^{-1} \mathrm{~mm} / \mathrm{min}$, and the preload is $0.1 \mathrm{~N}$. After tests, the tensile fracture was observed by SEM. Microhardness was measured by an instrumented universal hardness tester under the test load of $1 \mathrm{~N}$ for $15 \mathrm{~s}$. Take the diffusion bonding interface as the center, measure microhardness values every $0.5 \mathrm{~mm}$ and compare the changes. The deformation ratio is obtained by measuring the thickness of bonding specimens. The calculation formula of deformation ratio is:

$\varepsilon_{h}=\frac{h_{0}-h_{1}}{h_{0}} \times 100 \%$

where $\varepsilon_{h}$ is deformation ratio, $h_{0}$ is height before bonding, $h_{1}$ is height after bonding.

\section{Results and discussion}

\subsection{Microstructure}

In general, the quality of diffusion bonding is mainly affected by the following three factors: bonding temperature, holding

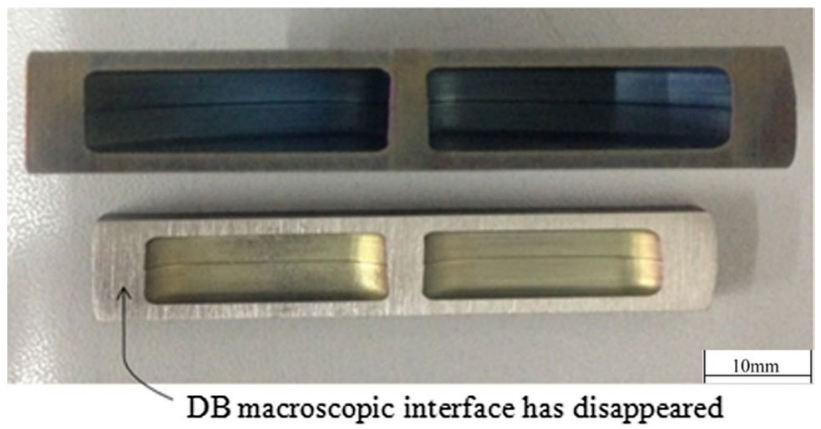

Fig. 6 Macroscopic picture of diffusion bonding specimens joints

time and bonding pressure. In particular, temperature and time are the most important factors [32]. This paper focuses on the effect of these two main factors on diffusion bonding quality of TC4 alloy hollow structures.

The 5 sets of experiment specimens in Table 3, have reached a good bonding on the macro-scale without any macroscopic defects. Cut the specimens by WEDM, and it is observed that the macroscopic interface has disappeared (Fig. 6).The preliminary stress test was carried out, and the specimens were well bonded.

Figure 7 shows the microstructure of the TC4 alloy hollow structure at diffusion bonding temperature of $800^{\circ} \mathrm{C}$, $850^{\circ} \mathrm{C}$ and $900^{\circ} \mathrm{C}$. The magnification is 200 times, pressure of diffusion bonding is $12 \mathrm{MPa}$, and holding time is $30 \mathrm{~min}$. The pictures show that the quality of diffusion bonding is getting better as the bonding temperature increases. The interface of joint is obvious at $800^{\circ} \mathrm{C}$. The voids are dense and large in size, and they were observed into strips at low magnification. At $850^{\circ} \mathrm{C}$, the joint quality has been obviously better. There are only a few voids at the joint and the size is smaller. When the bonding temperature is $900^{\circ} \mathrm{C}$, no void was observed under the microscope, which indicates that the material on both sides of the joint has been well bonded. The effect of temperature on diffusion bonding can be expressed by Arrhenius formula in kinetic theory [32, 33]:

$D=D_{0} \exp (-Q / R T)$

where $D$ is diffusion coefficient, $D_{0}$ is pre-exponential factor, $Q$ is volume diffusion activation energy, $R$ is gas constant, and $T$ is bonding temperature. From Eq. (3), the higher diffusion bonding temperature, the greater diffusion coefficient, this means diffusion rate is greater. However, excessive temperature will reduce the performance of joint, so it is necessary to obtain appropriate temperature parameters according to the specific conditions by test.

Figure 8 shows the microstructure of the TC 4 alloy hollow structure at holding time of 10, 20 and $30 \mathrm{~min}$. The magnification is 500 times, bonding temperature is $850^{\circ} \mathrm{C}$, 

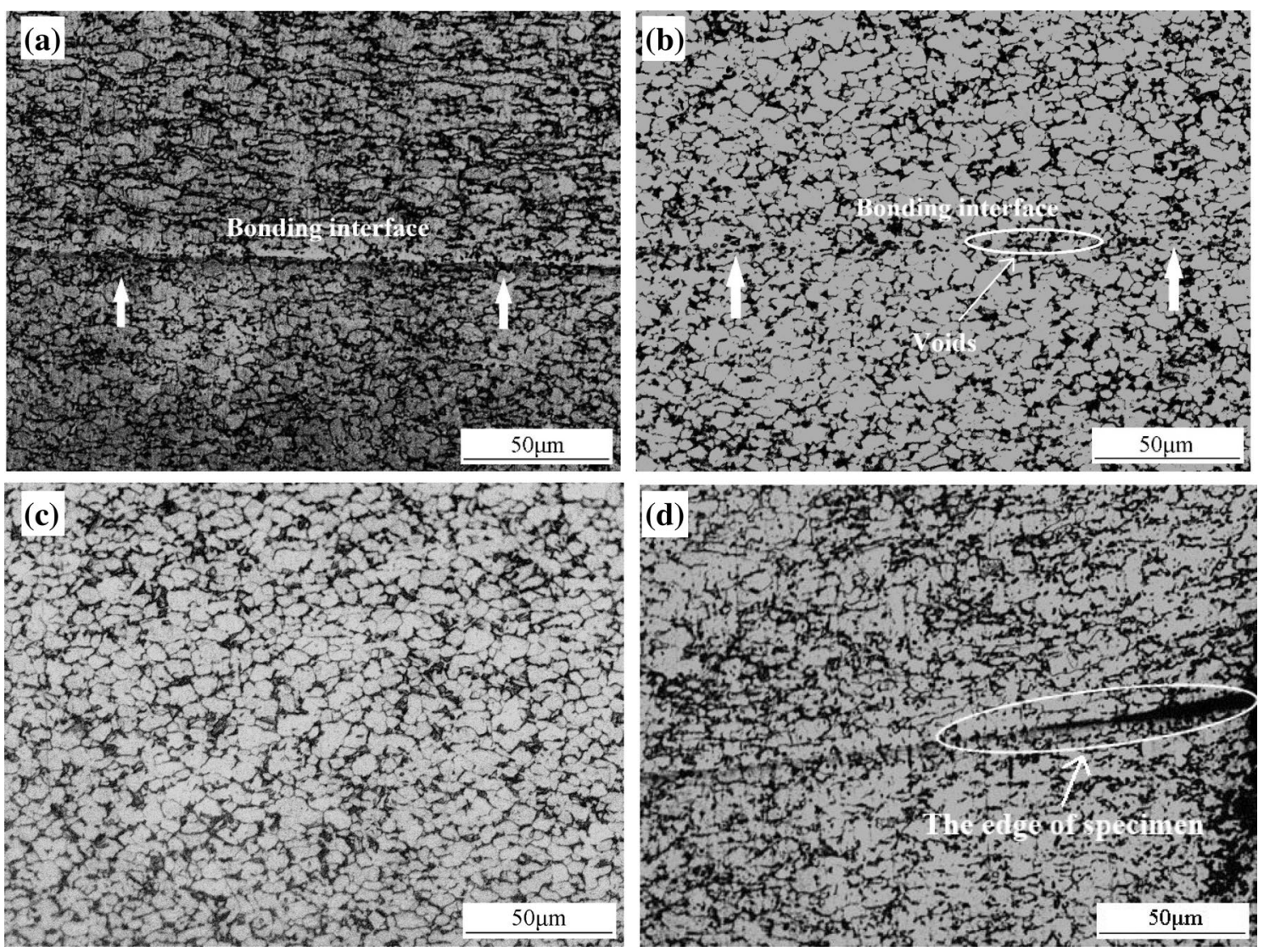

Fig. 7 Microstructures of diffusion bonding joints under different temperature: a $800{ }^{\circ} \mathrm{C} ; \mathbf{b} 850{ }^{\circ} \mathrm{C} ; \mathbf{c} 900{ }^{\circ} \mathrm{C} ; \mathbf{d}$ Microstructure of the edge of diffusion bonding specimen

and pressure is $12 \mathrm{MPa}$. As shown in the figure, the quality of diffusion bonding joint has improved as the holding time becomes longer. When the holding time is $10 \mathrm{~min}$, there are some larger size voids at the interface of bonding joint, and the voids are connected into strips. These stripshaped and unbounded defects have a great bad effect on the mechanical properties of products, so the defects must be avoided in production. When the holding time is $20 \mathrm{~min}$, the number of voids at bonding joint is decrease. The voids are round and the distribution is dispersed. There were no strip-shaped and unbounded defects found. This indicates that the quality of diffusion bonding is getting better. When the holding time is $30 \mathrm{~min}$, only a small amount of voids exist at the joint, and the quality of diffusion joint is good. From the comparison of Fig. 8, with the longer holding time, the grain of the material has a certain growth, but it is not very obvious. The effect of holding time on diffusion bonding can be expressed by the following equation $[33,34]$ :

$X=k\left(t-t_{D}\right)^{\frac{1}{2}}$ where $X$ is atomic diffusion distance, $k$ is rate constant, $t$ is holding time, $t_{D}$ is diffusion delayed reaction time.

The change of bonding ratio with diffusion bonding temperature and holding time is shown in Fig. 9 [Calculated by Eq. (1)]. It is more obvious from Fig. 9 that with the increase in bonding temperature and holding time, the joint interfacial bonding ratio is improved to a certain extent. At the conditions of bonding temperature $900^{\circ} \mathrm{C}$, holding time $30 \mathrm{~min}$, pressure $12 \mathrm{MPa}$, the joint bonding ratio has reached $98 \%$. Under the same conditions, the bonding ratio of $850{ }^{\circ} \mathrm{C}$ reached $92 \%$. It is observed by optical microscope that under the influence of pretreatment, some voids are not closed the edge of the specimen due to insufficient contact between the bonding interfaces (Fig. 7d). Therefore, even under the proper process parameters, the bonding ratio of whole specimen does not achieve $100 \%$. However, the joint interfacial bonding ratio is high after leaving the edge and the voids at the interface disappear completely. The bonding ratio is basically $100 \%$. In addition, under the conditions of $850^{\circ} \mathrm{C}, 20$ min and $12 \mathrm{MPa}$, joint bonding ratio reached over $86 \%$. Only a few voids were observed under microscope, the whole bonding quality of joint was better. 

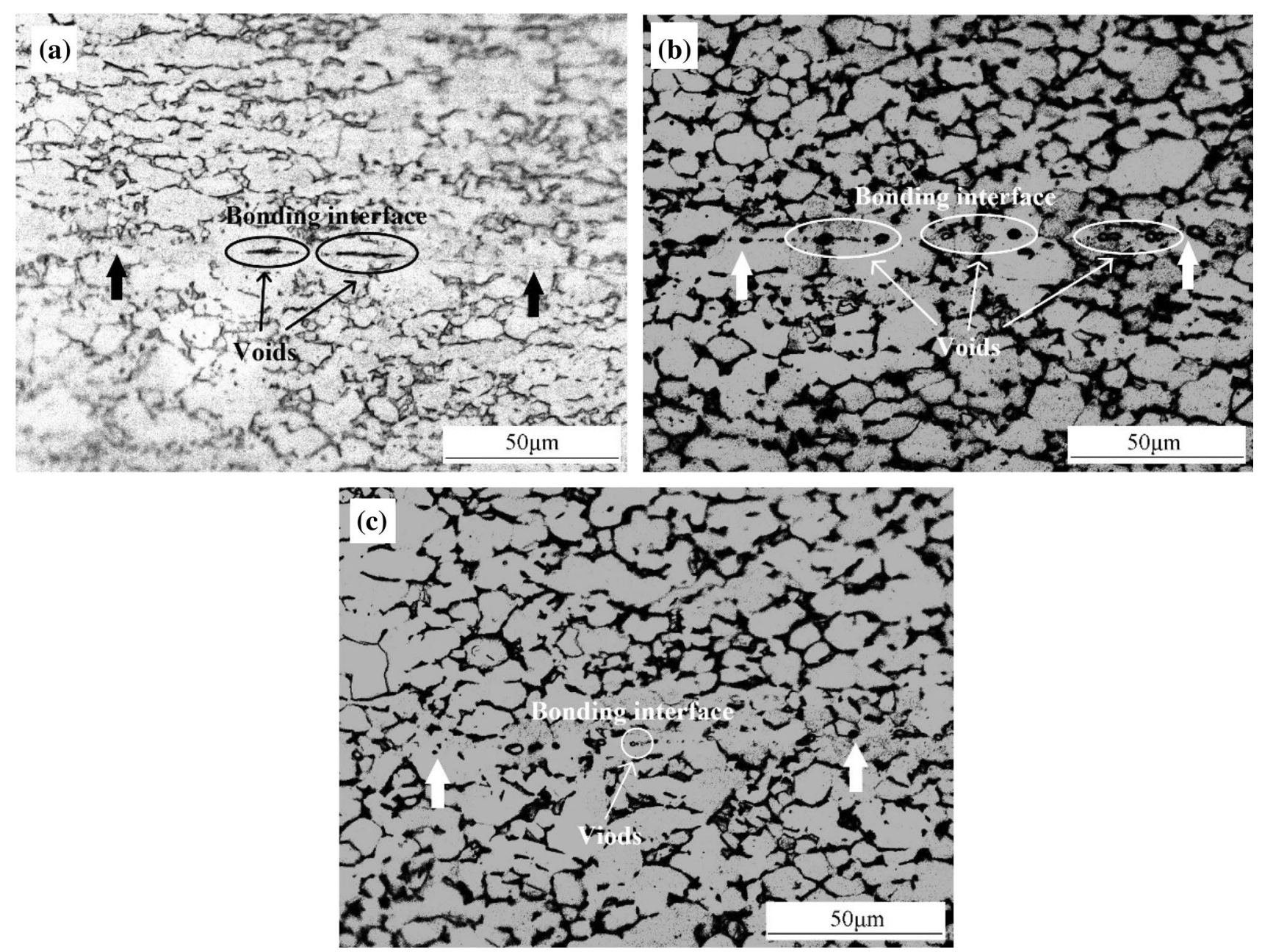

Fig. 8 Microstructures of diffusion bonding joints under holding time: a10min; b20min; c30min

By the above analysis of the experiments show that when the diffusion bonding temperature is more than $850^{\circ} \mathrm{C}$, holding time is more than $20 \mathrm{~min}$ and pressure is proper, the TC4 alloy hollow structure specimen can get a good bonding quality on the basis of joint interfacial bonding ratio. Because the specimen has unavoidable error in the mechanical processing, especially in the pretreatment stage, the quality of the edge of joint is poor. Therefore, a certain allowance should be left when processing in order to trim the edge of product after diffusion bonding. The bonding ratio can reach $96 \%-100 \%$ after the treatment.

\subsection{Mechanical properties}

\subsubsection{Tensile mechanical properties}

Figure 10a shows the change in the tensile strength of joint when the bonding temperature is $800{ }^{\circ} \mathrm{C}, 850^{\circ} \mathrm{C}$ and $900^{\circ} \mathrm{C}$. As shown in Fig. 10a, the tensile strength of the joint increases as the bonding temperature increases in the range of $800^{\circ} \mathrm{C}-900^{\circ} \mathrm{C}$. When the temperature is $900{ }^{\circ} \mathrm{C}$, the tensile strength reached $979 \mathrm{MPa}$, which is basically the same as the tensile strength $(980 \mathrm{MPa})$ of the base metal. And at $850^{\circ} \mathrm{C}$, the tensile strength is $952 \mathrm{MPa}$, which is more than $97 \%$ of tensile strength of the base metal. The tensile tests and microstructural observation show that the joints obtained under these two parameters not only achieved almost complete diffusion bonding on the micro-scale, but also have good mechanical properties. The tensile strength is basically the same as the base metal and has met the product requirements. When the bonding temperature is $800{ }^{\circ} \mathrm{C}$, the tensile strength of diffusion bonding specimen is only $588 \mathrm{MPa}$. The reason is that the diffusion bonding is not complete enough at this temperature, and there are many voids at the interface. However, when the temperature rises from $800{ }^{\circ} \mathrm{C}$ to $850^{\circ} \mathrm{C}$, the tensile strength of the specimen increases greatly and basically reaches the tensile strength of the base metal. This further proves that the $850-900^{\circ} \mathrm{C}$ is the suitable temperature for diffusion bonding. 
Fig. 9 Bonding ratio of joints under different conditions: a At different temperatures for $30 \mathrm{~min}, 12 \mathrm{MPa}$; b At $850^{\circ} \mathrm{C}$, $12 \mathrm{MPa}$ for different time
Fig. 10 Tensile strength of joints under different conditions: a At different temperatures for $30 \mathrm{~min}, 12 \mathrm{MPa}$; b At $850^{\circ} \mathrm{C}, 12 \mathrm{MPa}$ for different time
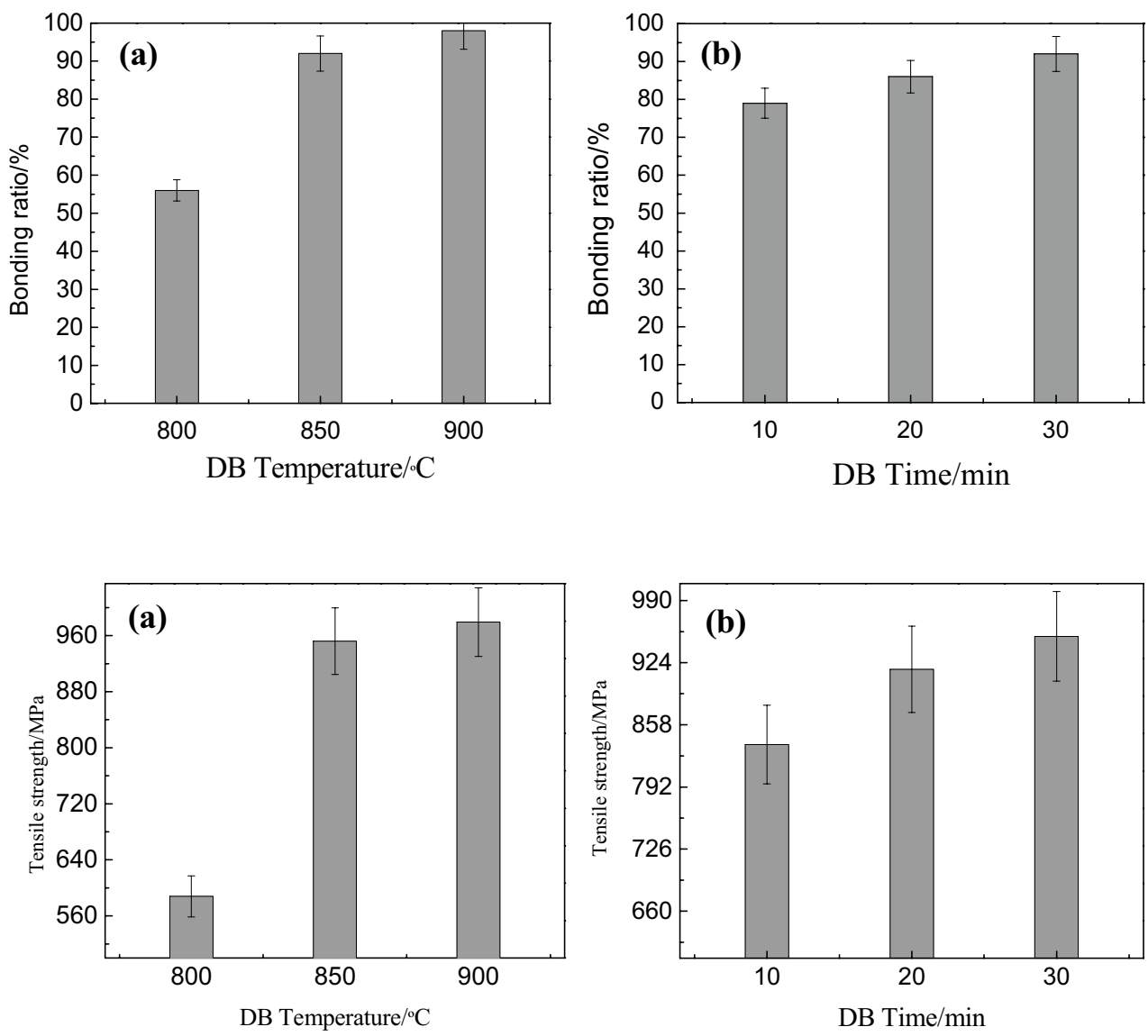

Figure $10 \mathrm{~b}$ shows the change in the tensile strength of joint when the bonding time is 10,20 and 30 min. From Fig. 10b, the tensile strength of the joints increases gradually with the prolonging of holding time in 10-30 min. When the holding time is $10 \mathrm{~min}$, the tensile strength of the diffusion joint specimen is $837 \mathrm{MPa}$, which has reached $85 \%$ of tensile strength of the base metal. When the holding time is $20 \mathrm{~min}$ and $30 \mathrm{~min}$, the tensile strength of joints is $917 \mathrm{MPa}$ and $952 \mathrm{MPa}$, respectively. Within a certain range, the prolonged holding time leads to more sufficient diffusion bonding. It causes the tensile strength of the joints to rise steadily.

Figure 11 is true stress-strain curves of the diffusion bonding specimens obtained by tensile tests. The diffusion bonding process parameters are temperature $900^{\circ} \mathrm{C}$ and $850^{\circ} \mathrm{C}$, holding time $30 \mathrm{~min}$ and pressure $12 \mathrm{MPa}$. The stress-strain curves show that the specimens do not yield significantly during the tensile test. Figure 12 is the macroscopic morphology and microstructure of tensile fracture of specimens. It can be seen from the diagram that the dimples are deep and dense, and the fracture presents typical ductile fracture.

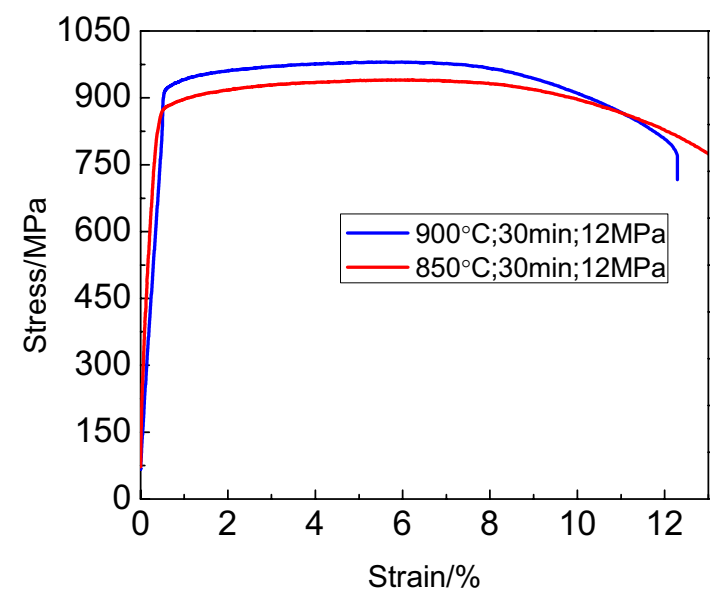

Fig. 11 Stress-strain curves

\subsubsection{Microhardness profiles}

Figure 13 shows the change in microhardness at the interface and on both sides of the joint. Microhardness measurements were performed at each point of the $0.5 \mathrm{~mm}$ at the center of the interface of the diffusion bonding joint (see Fig. 14). Three points are taken in parallel in 

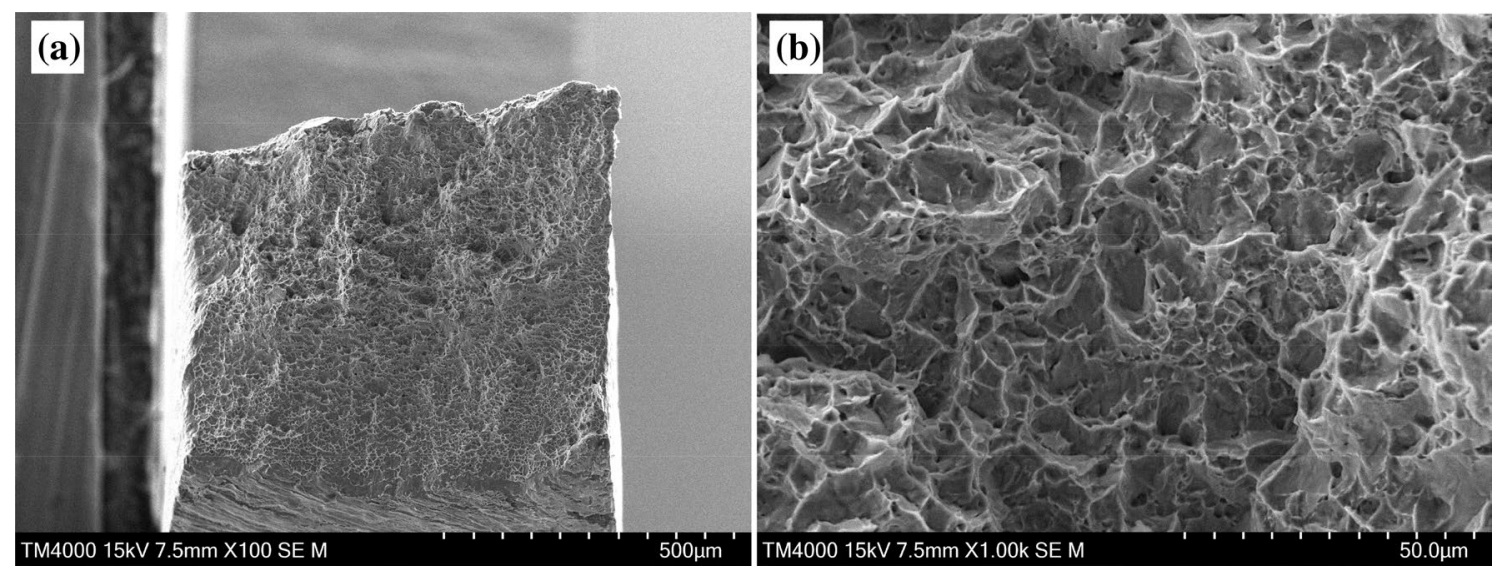

Fig. 12 SEM fractographs of tensile specimens: a Macroscopic morphology; b Micro-morphology

Fig. 13 Microhardness values of joints under different conditions: a At different temperatures for $30 \mathrm{~min}, 12 \mathrm{MPa}$; $\mathbf{b}$ At $850^{\circ} \mathrm{C}, 12 \mathrm{MPa}$ for different time
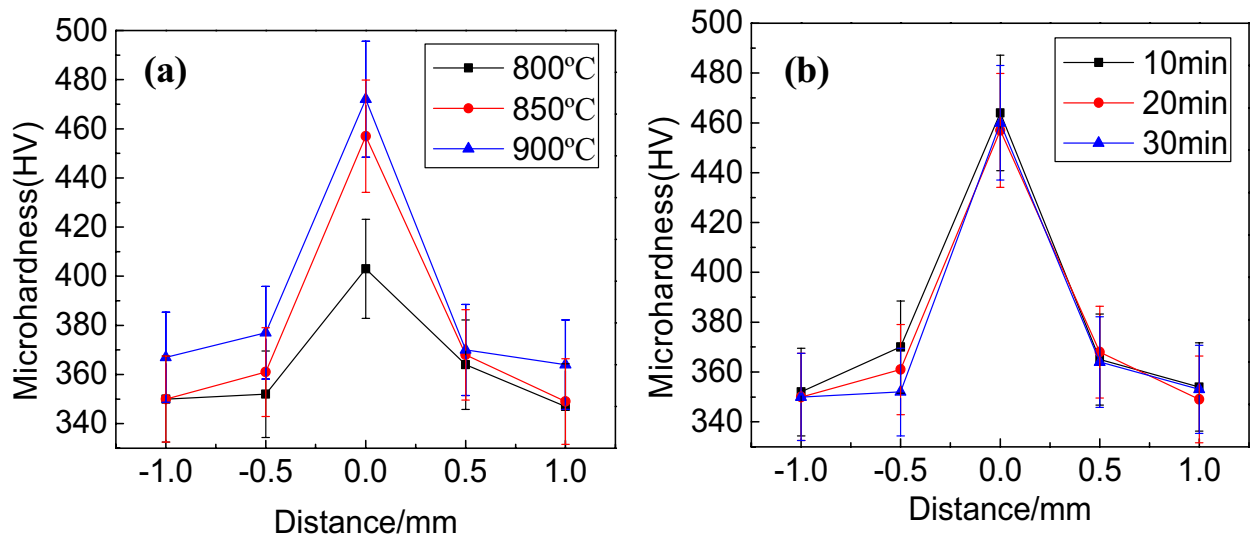

each position, and their average values are calculated to obtain the microhardness of the position. It can be seen from Fig. 12, even under the effect of different bonding temperature and holding time, the peak value of microhardness of diffusion bonding joint also occurs at the joint interface. And the closer to the joint interface, the higher the microhardness value. The main reason for this phenomenon is likely to be the pressure applied during the holding stage, which results in a large microscopic plastic deformation of the grain near the interface, lead to grain refinement occurs. The secondary reason is likely to be that impurities and oxides are not completely cleaned up at the interface, which results in a locally increase in microhardness after diffusion bonding.

From Fig. 13a, the microhardness of the joint increases integrally as the temperature increases. When the temperature is $800^{\circ} \mathrm{C}$, the range of microhardness changes from HV347-403. At $850^{\circ} \mathrm{C}$, the microhardness range is HV349-457. At $900{ }^{\circ} \mathrm{C}$, the microhardness range is HV364-472, and the maximum microhardness is reached at the interface area. The value of microhardness of the

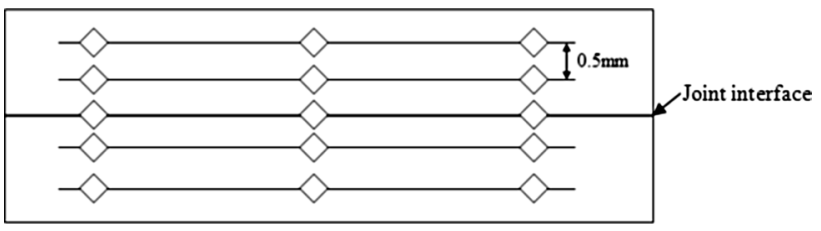

Fig. 14 Distribution of microhardness values measurement points

joint interface is obviously low at $800^{\circ} \mathrm{C}$. This is because the diffusion bonding is not sufficiently at this temperature, so that there are many voids at the interface, which leads to lower microhardness. The increase in temperature accelerated the microscopic plastic deformation of the interface and the contact area became larger. Therefore, the diffusion speed of the interface atoms is enhanced, and the grain refinement is further refined so that the microhardness increases. From Fig. 13b, the microhardness of the joint decreases as the holding time increases. The maximum microhardness value is HV365 at the holding time of $30 \mathrm{~min}$. Prolonging holding time leads to the 
Fig. 15 Deformation ratio of joints under different conditions: a At different temperatures for $30 \mathrm{~min}, 12 \mathrm{MPa}$; $\mathbf{b}$ At $850^{\circ} \mathrm{C}, 12 \mathrm{MPa}$ for different time; c The physical picture of diffused bonding specimens
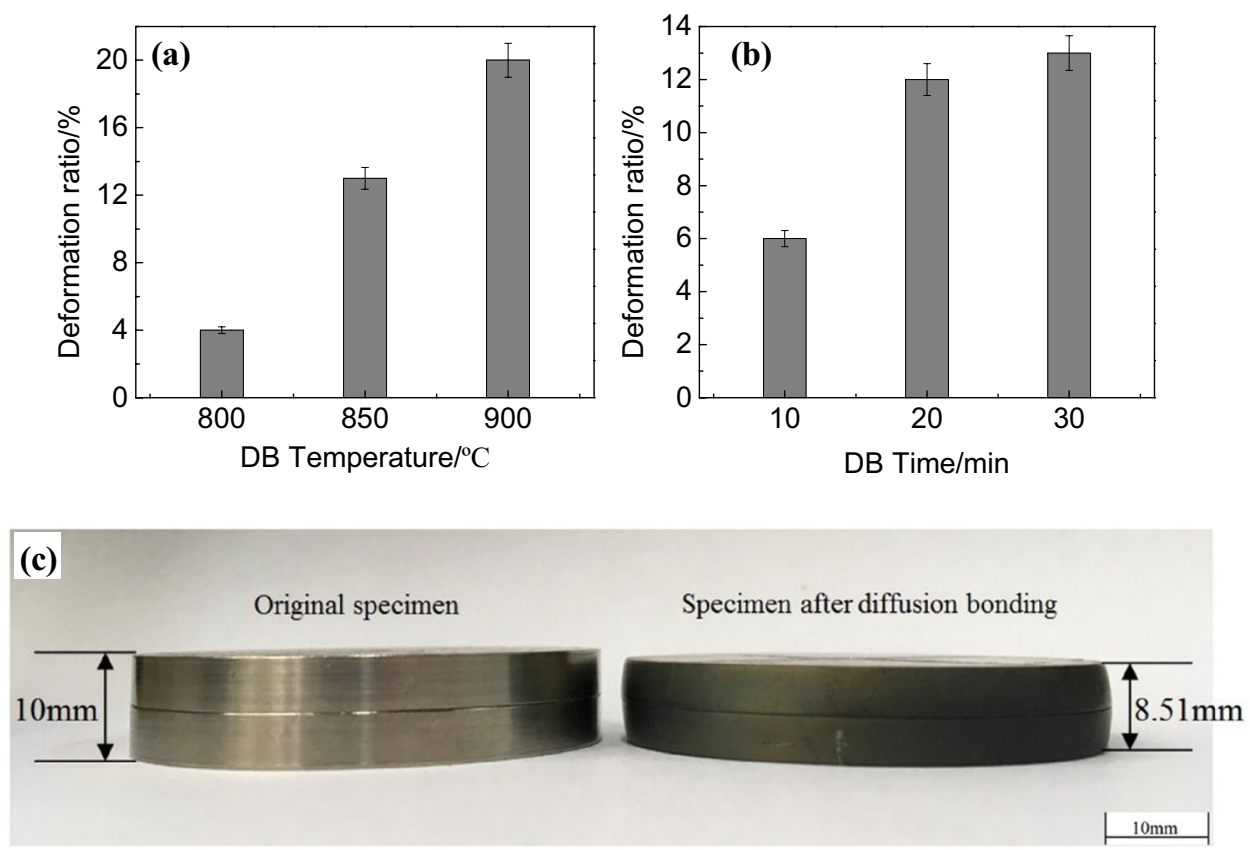

growth of metal grain, which results in the decrease in microhardness. However, the growth of grain is not very serious because the range of holding time is small in this experiment. Therefore, the change of microhardness value is not very large. Through the microhardness test, it can be concluded that the bonding temperature has more effect on the microhardness value than the holding time.

\subsubsection{Deformation ratio}

Figure 15 shows the deformation ratio of the joint under different diffusion bonding parameters [Calculated by Eq. (2)]. The clearance between the upper and lower die of the diffusion bonding die is $2 \mathrm{~mm}$ in the experiment, which means the maximum deformation of specimens is $2 \mathrm{~mm}$. Due to these deformations are all irreversible, the maximum deformation ratio can reach $20 \%$. From Fig. 15, it is found that the deformation ratio of specimen increases with the increase in bonding temperature and holding time, but their effect degree is different. As shown in Fig. $15 \mathrm{a}$, bonding temperature has a great effect on the deformation ratio. With the increase in temperature, the resistance to deformation of alloy decreases rapidly. The deformation ratio is only $4 \%$ at $800^{\circ} \mathrm{C}$ and $13 \%$ at $850{ }^{\circ} \mathrm{C}$. At $900{ }^{\circ} \mathrm{C}$, the maximum deformation rate has reached $20 \%$. It indicates that the deformation ratio has been too large at this temperature, which will have a bad effect on the forming of the products. As shown in Fig. 15b, with the increase in holding time, the deformation ratio increases gradually and reaches the maximum value of $13 \%$ at $30 \mathrm{~min}$. It is indicated that the effect of holding time on deformation is not large. Under the condition of proper bonding temperature, prolonging the holding time properly will not cause excessive deformation ratio of products.

\section{Conclusions}

(1) TC4 alloy hollow structure was designed based on the rudder surface, and its diffusion bonding experiment was carried out. In the process of diffusion bonding temperature $850{ }^{\circ} \mathrm{C}$, holding time $20-30 \mathrm{~min}$ and bonding pressure $12 \mathrm{MPa}$, a good quality diffusion bonding joint has been obtained. When the holding time is $30 \mathrm{~min}$, the joint bonding ratio is more than $92 \%$, the tensile strength is $952 \mathrm{MPa}$, and the deformation ratio is maintained at about $10 \%$.

(2) Diffusion bonding temperature is the main factor affecting the diffusion bonding quality of TC4 hollow structure. The higher bonding temperature is, the higher bonding ratio is, and the tensile strength is also improved with it. However, the excessive temperature will increase the deformation ratio of hollow structural parts. The experimental results show that the bonding temperature should not exceed $900^{\circ} \mathrm{C}$, when this kind of TC4 hollow structure is formed by diffusion bonding. 
(3) Diffusion bonding holding time has a great effect on joint bonding quality. As the holding time increases, the joint bonding ratio increases, which results in the increase in tensile strength. However, if the holding time is too long, it will lead to grain growth, lower hardness, and have a bad effect on tensile strength. Meanwhile, excessive holding time reduces the production efficiency, so the holding time should be shortened as much as possible.

(4) The microhardness of the TC4 alloy hollow structural joint shows the trend of "high in the middle and low on both sides" after diffusion bonding. It is because the process of diffusion bonding leads to grain refinement at the interface. When the temperature increases, the whole microhardness of the joint increases, and when the holding time is prolonged, the whole microhardness decreases.

Acknowledgements The authors would like to acknowledge the supporters of the project that AVIC Beijing aeronautical manufacturing technology research institute and School of Materials Science and Engineering of USST (University of Shanghai for Science and Technology).

\section{Compliance with ethical standards}

Conflict of interest The authors declare that they have no conflict of interest.

\section{References}

1. Bhaskar Dutta, Francis H. Froes (2016) Additive Manufacturing of Titanium Alloys: State of the Art, Challenges and Opportunities.

2. Cui Chunxiang Hu, BaoMin ZL, Shuangjin L (2011) Titanium alloy production technology, market prospects and industry development. Mater Des 32(3):1684-1691

3. Leder $\mathrm{O}$ (2017) Vertical integration: titanium products for the aircraft industry. In: Richter K, Walther J (eds) Supply chain integration challenges in commercial aerospace. Springer International Publishing, Cham

4. Jia-Ning Li, Ji-Shuai Li, Wen-Jun Qi, Ke-Gao L (2019) Characterization and mechanical properties of thick TC4 titanium alloy sheets welded joint by vacuum EBW. Vacuum 168:108812

5. Li GR, Li YM, Wang FF, Wang HM (2015) Microstructure and performance of solid TC4 titanium alloy subjected to the high pulsed magnetic field treatment. J Alloy Compd 644:750-756

6. Chen F, Gu Y, Xu G et al (2019) Improved fracture toughness by microalloying of Fe in Ti-6Al-4V. Mater Des 185:108251

7. Wang KL, Lu SQ, Fu MW, Li X, Dong XJ (2010) Identification of the optimal $(a+\beta)$ forging process parameters of Ti-65Al$35 \mathrm{Mo}-15 \mathrm{Zr}-03 \mathrm{Si}$ based on processing-maps. Mater Sci Eng 527(27):7279-7285

8. Yip WS, To S (2018) Sustainable manufacturing of ultra-precision machining of titanium alloys using a magnetic field and its sustainability assessment. Sustain Mater Technol 16:38-46
9. Yip WS, To S (2020) Preliminary investigation on ultra-precision diamond turning of titanium alloys using thermoelectric cooler fixture. J Manuf Process 58:187-192

10. Xie Z, Duan FL (2020) Material processing for low thermal conductivity for advanced aero-engine applications. Res Mater 6:100079

11. Goel S, Xi-chun L, Reuben RL, Pen H (2012) Influence of temperature and crystal orientation on tool wear during single point diamond turning of silicon. Wear 284-285(4):65-72

12. Li L, Li J, Tang B et al (2019) Microstructure evolution and mechanical properties of diffusion bonding high $\mathrm{Nb}$ containing TiAl alloy to Ti2AINb alloy. Vacuum 164:140-148

13. Chandrappa K, Kant R, Ali R, Vineth K (2020) Optimization of process parameter of diffusion bonding of Ti-Al and Ti-Cu. Mater Today Proc 27(2):1689-1695

14. Zhi-hao Du, Zhang Kai-feng Lu, Zhen J-S (2018) Microstructure and mechanical properties of vacuum diffusion bonding joints for $y$-TiAl based alloy. Vacuum 150:96-104

15. Balogh Z , Schmitz G (2014). Diffusion in Metals and Alloys, Physical Metallurgy.

16. Yuan L, Xiong J, Peng Y et al (2019) Microstructure and mechanical properties in the solid-state diffusion bonding joints of $\mathrm{Ni3Al}$ based superalloy. Mater Sci Eng 772:138670

17. Aboudi D, Lebaili S, Taouinet M, Zollinger J (2017) Microstructure evolution of diffusion welded 304L/Zircaloy 4, with copper interlayer. Mater Des 116:386-394

18. Zhao-rong LIN, Zhong-yuan ZHANG, Wei-dong HUANG (1992) An investigation of diffusion bonding under superplastic condition for Ti-6Al-4V titanium alloy. Acta Aeronaut ET Astronaut Sin 13(5):288-295

19. Hao ZHANG, Jing-long LI, Ping-yi MA, Jiangtao XIONG, Fu-sheng ZHANG (2018) Study on microstructure and impact toughness of TC4 titanium alloy diffusion bonding joint. Vacuum 152:272-277

20. Yuan L, Xiong J, Peng Y, Li Z, Li J (2020) Modeling void closure in solid-state diffusion bonding of TC4 alloy. Vacuum 173:109120

21. Yakushina E, Reshetov A, Semenova I, Polyakova V, Rosochowski A, Valiev R (2018) The influence of the microstructure morphology of two phase Ti-6Al-4V alloy on the mechanical properties of diffusion bonded joints. Mater Sci Eng 772:138670

22. Han WB, Zhang KF, Wang GF (2005) Superplastic forming and diffusion bonding for multilayer structure of Ti-6Al-4V alloy. J Aeronaut Mater 25(6):29-32

23. Dursun T, Soutis C (2014) Recent developments in advanced aircraft aluminium alloys. Mater Des 56(4):862-871

24. Singh P, Pungotra $H$, Kalsi NS (2017) On the characteristics of titanium alloys for the aircraft applications. Mater Today Proc 4(8):8971-8982

25. Veiga C, Davim JP, Loureiro AJR (2012) Properties and applications of titanium alloys: a brief review. Rev Adv Mater Sci 32(2):133-148

26. Zhun-li T, Li-shuo B, Bing-zhe B, Bing Z, Zhi-qiang Li, Hong-liang H (2016) Fabrication of lattice truss structures by novel superplastic forming and diffusion bonding process in a titanium alloy. Mater Des 92:724-730

27. Xue-song Z, Yong-jun C, Jun-ling Hu (2018) Recent advances in the development of aerospace materials. Prog Aerosp Sci 97:22-34

28. Bing Z, Zhiqiang $\mathrm{L}$, Hongliang $\mathrm{H}$ et al (2010) Three dimensional FEM simulation of titanium hollow blade forming process. Rare Metal Mater Eng 39(6):963-968

29. Zhao Z, Jiuhua XU, Yucan FU et al (2018) An investigation on adaptively machining the leading and tailing edges of an SPF/ 
DB titanium hollow blade using free-form deformation. Chin J Aeronaut 031(001):178-186

30. Zhi-hao Du, Shao-song J, Zhang Kai-feng Lu, Zhen L-Y, Da-lin Z (2016) The structural design and superplastic forming/diffusion bonding of Ti $2 \mathrm{AINb}$ based alloy for four-layer structure. Mater Des 104:242-250

31. Takahashi Y, Takahashi K, Nishiguchi K (1991) A numerical analysis of void shrinkage processes controlled by coupled surface and interface diffusion. Acta Metall Mater 39(12):3199-3216

32. Ya-jiang LI (2007) Special connection technology[M]. Mechanical Industry Press, Beijing
33. Yong Du, Chang YA, Bai-yun $\mathrm{H}$, Wei-ping $\mathrm{G}$, Jin Zhan-peng $X u$, Hong-hui Y-H, Yong L, Yue-hui He, Xie FY (2003) Diffusion coefficients of some solutes in fcc and liquid Al: critical evaluation and correlation. Mater Sci Eng 363(1-2):140-151

34. Kang-sheng HE, Xiong-fu CAO (1986) Welding of Dissimilar Metal[M]. Mechanical Industry Press, Beijing

Publisher's Note Springer Nature remains neutral with regard to jurisdictional claims in published maps and institutional affiliations. 